\title{
CHARACTERISTICS OF CORRUGATION IN SHANGHAI METRO AND SUGGESTED MAINTENANCE THRESHOLD FOR AMPLITUDE
}

\author{
WANYI LIU ${ }^{1}$, HAIFENG LI ${ }^{1,2}$, YUDE XU ${ }^{1}$, WANQING ZHANG ${ }^{3}$, SIHAN YAN ${ }^{1}$, FENGYU LI ${ }^{1} \& J^{1}$ UNXING \\ $\mathrm{QIU}^{1}$ \\ ${ }^{1}$ Key Laboratory of Road and Traffic Engineering of the Ministry of Education, Tongji University, China. \\ ${ }^{2}$ Department of Transportation Engineering, Tongji Zhejiang College, China. \\ ${ }^{3}$ Vibration and Noise Research Department, Shanghai Marine Diesel Engine Research Institute, China.
}

\begin{abstract}
To find out the relationship between the track structure parameters and rail corrugation type and put forward a reasonable maintenance threshold for the amplitude of rail corrugation, surveys on rail corrugation by rail static and dynamic tests were carried out on Shanghai Metro recently. Based on the in situ data, the wavelength and amplitude of rail corrugation were calculated and analysed by different categories according to their service conditions. Investigation data and its analysis show that different track structure parameters, such as ballast, fastener, curve radius, etc., can affect the amplitude and wavelength in pretty different ways. In order to know the development trend in rail corrugation, statistical significance on the distribution of amplitude and dynamic data is calculated, the distribution of amplitude at certain wavelengths is figured out, and accordingly a reasonable threshold of the amplitude maintenance is put forward.
\end{abstract}

Keywords: in situ tests, maintenance threshold, rail corrugation, subway, track structure.

\section{INTRODUCTION}

Rail corrugation is a normal phenomenon in the world but appears now to be substantially understood, and lots of researches have been done on its cause and treatments. Rail corrugation is quasi-sinusoidal irregularity where the wavelength is less than $1 \mathrm{~m}$ [1]. Grinding corrugated rail reduced the power spectrum of railhead roughness by about 2 orders of magnitude of wave numbers up to about 25 cycles $\mathrm{m}^{-1}$ and by about 1 order of magnitude of higher wave numbers [2]. According to Sato et al. [3], for five out of corrugation's six categories, not only characteristics but also causes and even its treatments are identified. According to their opinion for the sixth category (roaring rail-type corrugation), a wavelength-fixing mechanism yet had to be pursued. Torstensson [4] monitored rail roughness in a curve with radius $120 \mathrm{~m}$ in the Stockholm Metro and pointed out that roughness growth rate increased with the number of days after grinding until the measurement that was taken 300 days after grinding. Besides, corrugation does not consistently show uniformly increased magnitudes in the same sections of the curve as before grinding. Wang X. [5] did continue tests on corrugation's development of two different base plates, figuring out that the wavelengths of stiffness $90 \mathrm{MN} / \mathrm{m}$ and $60 \mathrm{MN} / \mathrm{m}$ are 80-100 $\mathrm{mm}$ and 160-185 mm, respectively. Cao [6] analysed the corrugation's characteristics of Shanghai Metro 1 and found out there existed huge differences between the two transition curves. 
Rail corrugations can increase vibrations and noises and multiple the costs for maintenance. In order to find out the characteristics of corrugation with different track structures and put forward a reasonable criterion for amplitude controlling, some surveys are carried out. Based on experimental data, characteristics of corrugation with various structures are analysed and amplitude thresholds which can be applied on maintenance are offered.

\section{SOURCE AND PRE-PROCESSING}

In this paper, data of sections with severe corrugation and their track structures and line conditions are recorded. Rail surface irregularities are measured with RMF 2.3E, which can identify wavelength of 10 to $300 \mathrm{~mm}$. This research covered 6 lines and 8 sections and some of them are measured continuously. Line conditions are shown in Table 1.

In dynamic in situ tests, stress and acceleration are measured for a train with different speeds. Measuring spots are shown in Fig. 1.

The measured rail corrugation data may contain some interference and some pre-processed works need to be done before performing a detailed analysis, which includes the following:

(a) Categorizing data based on working conditions: one working condition means these sections share the same track structure and similar curve radius.

(b) Eliminating trend term: due to error in the measure instrument and the influence of environment, rail irregularity shows trends of upward or downward movement. Raw data need to be fitted with least square method.

Table 1: Line conditions.

Line

$1,2,3,8,9,11$

Ballast

Monolithic track bed, normal bearing block, ballast, long sleeper buried, floating slab

Fastener

Vanguard, DTIII-2, WJ-2A, elastic rod-II, absorber, LORD

Curve radius (m)

$350,400-450,500,700,800,1200$
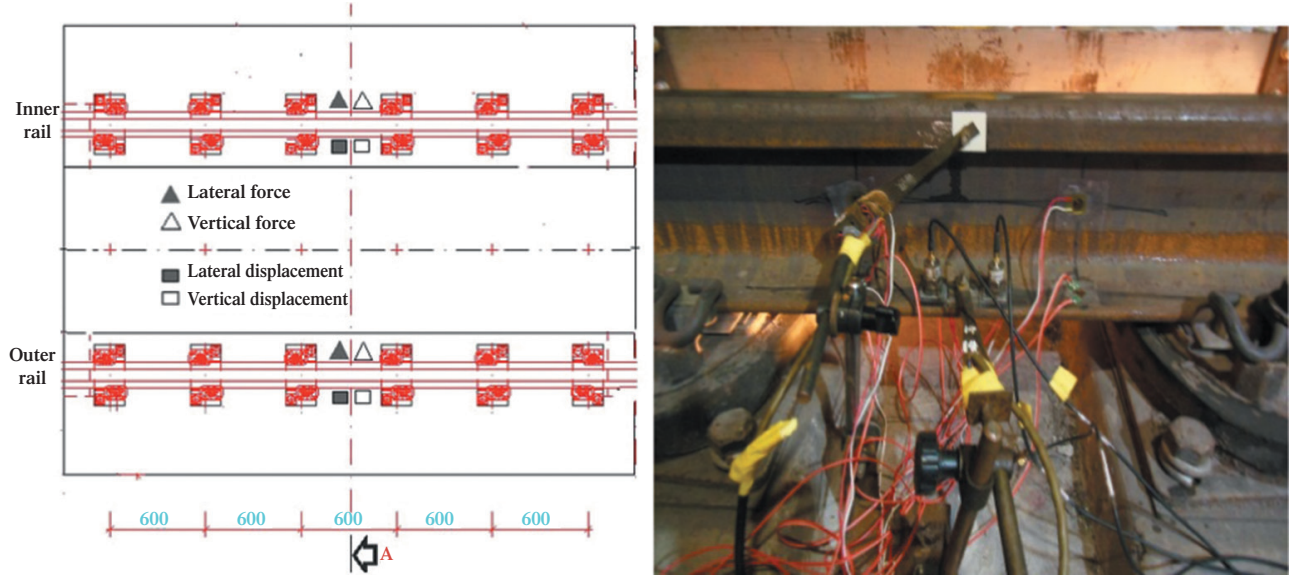

Figure 1: In situ tests. 
(c) Deleting effects of rail joints: identifying where these rail joints are and then deleting data of a certain range.

(d) Deleting abnormal data.

Data after pre-processing can be used to analyse corrugation's distribution and relationship with different working conditions.

\section{RELATIONSHIP BETWEEN CORRUGATION AND TRACK STRUCTURES}

\subsection{Relationship between corrugation and ballasts}

As shown in Fig. 2(a), amplitude of corrugation where monolithic track bed is utilized is smaller than that where floating slab is used as ballast. And in Fig. 2(b) when elastic-II and curve with radius $400-450 \mathrm{~m}$ is applied, amplitude of long sleeper buried is smaller than normal bearing block and ballast. In other conditions amplitude of monolithic track bed is smaller than long sleeper buried. In short, when we consider corrugation mainly, no matter which kind of fasteners and radius is used, monolithic track bed's amplitude is relatively short while ballast's is long

Figure 3(a) and (b) shows influences of ballast on wavelength when using DTIII-2 or elastic-II as fastener. When fastener is DTIII-2, wavelength of floating is shorter than that of monolithic track bed. When fastener is elastic-II, wavelength of long sleeper buried is the shortest and the wavelength of ballast is pretty long. In brief, the wavelength of floating slab is relatively short and the wavelength of ballast or normal bearing block is pretty long.
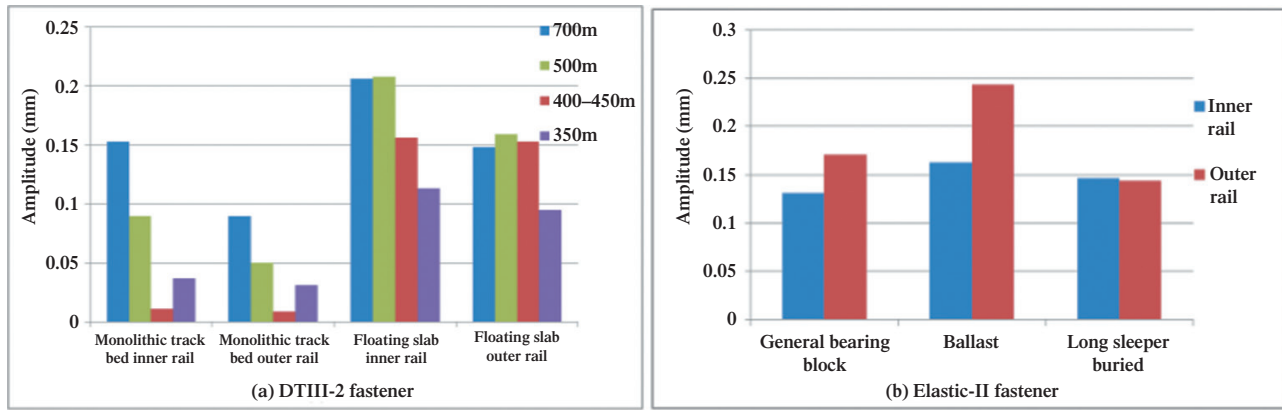

Figure 2: Amplitudes with different ballasts where certain fasteners are applied.
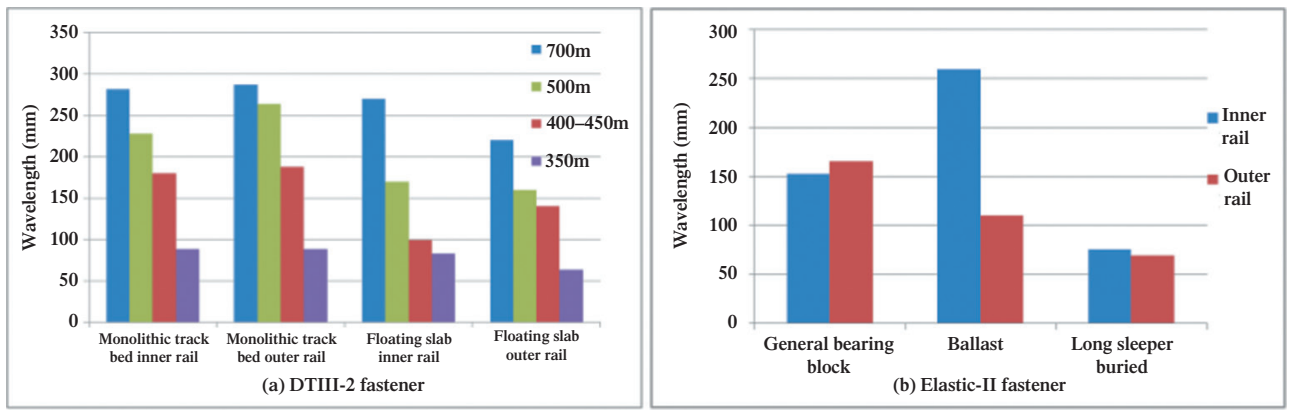

Figure 3: Wavelengths with different ballasts when certain fasteners are applied. 


\subsection{Relationship between corrugation and fasteners}

Figure 4 shows what will happen to different fasteners' amplitude when we use (a) floating slab and (b) monolithic track bed as ballast. When ballast and curve radius are the same, the amplitude of vanguard or absorber is smaller than the amplitude of DTIII-2.

What Fig. 5 shows is the wavelength of different fasteners when we use (a) floating slab and (b) monolithic track bed. We can easily find that wavelength of vanguard is the longest and that of absorber is the shortest.

\subsection{Relationship between corrugation and curve radius}

Actually, curve radius influences amplitude in different ways under different working conditions. Figure 6 shows that amplitude reaches its minimum where the curve radius is about 400-450 m when (a) monolithic track bed and DTIII-2 or (b) absorber is applied.
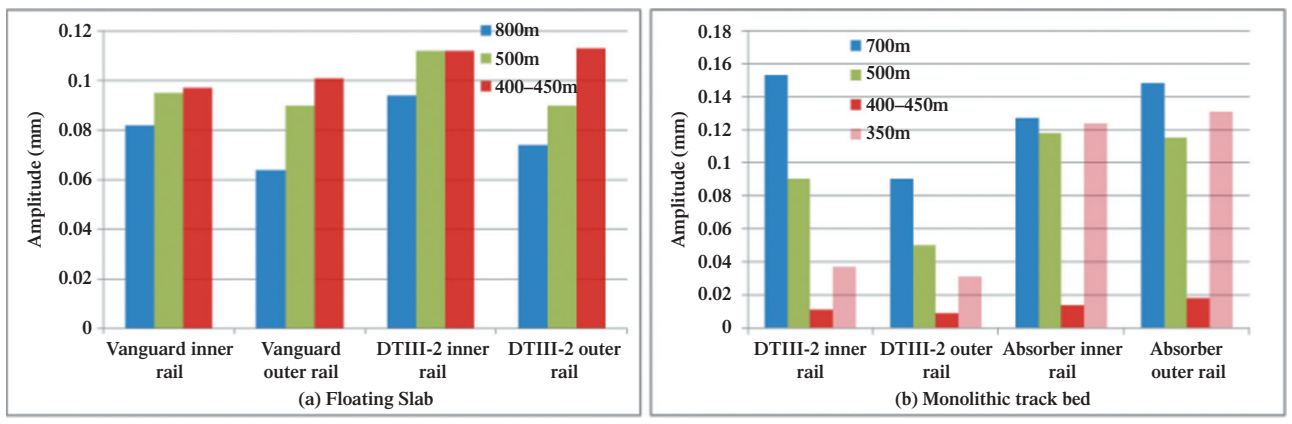

Figure 4: Amplitudes with different fasteners where certain ballasts are applied.
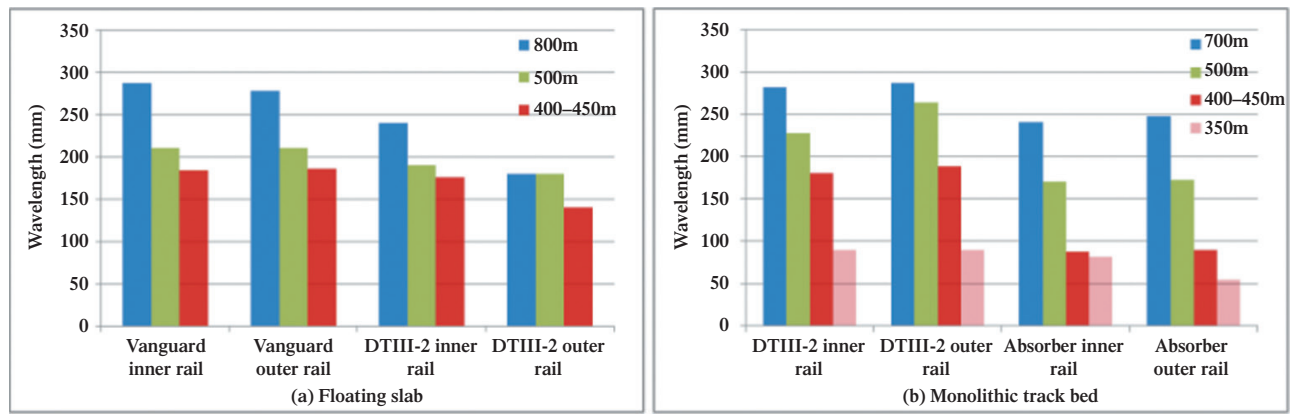

Figure 5: Wavelengths with different fasteners where certain ballasts are applied.
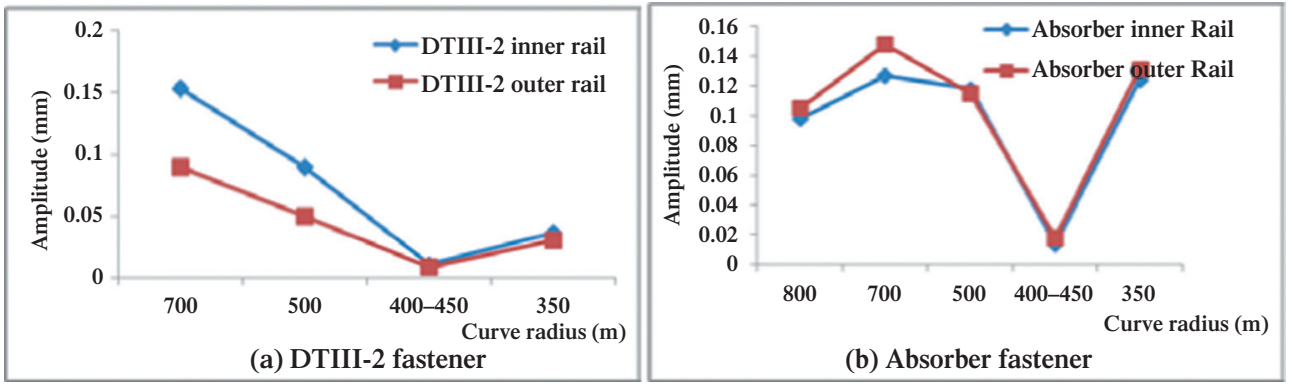

Figure 6: Amplitudes with different radius where monolithic track bed is applied. 


\section{COMPRAIL}

Figure 7 points out that wavelength decreases with decreased curve radius. Actually, wavelength shares the same rule when other kinds of ballast are applied.

\section{CORRUGATION CONTROLLING AND MAINTENANCE}

\subsection{Distribution of amplitude}

Statistical analysis was conducted on the corrugation of Shanghai Metro 8 and 11, contributions of which are shown in Figs. 8 and 9 and Table 2.

According to Figs. 8 and 9 and Table 2, contribution of amplitude of different wavelengths is standard normal distribution. If we set triple standards as the threshold, most of the portion is below $3 \%$, which is pretty reasonable for the operation.

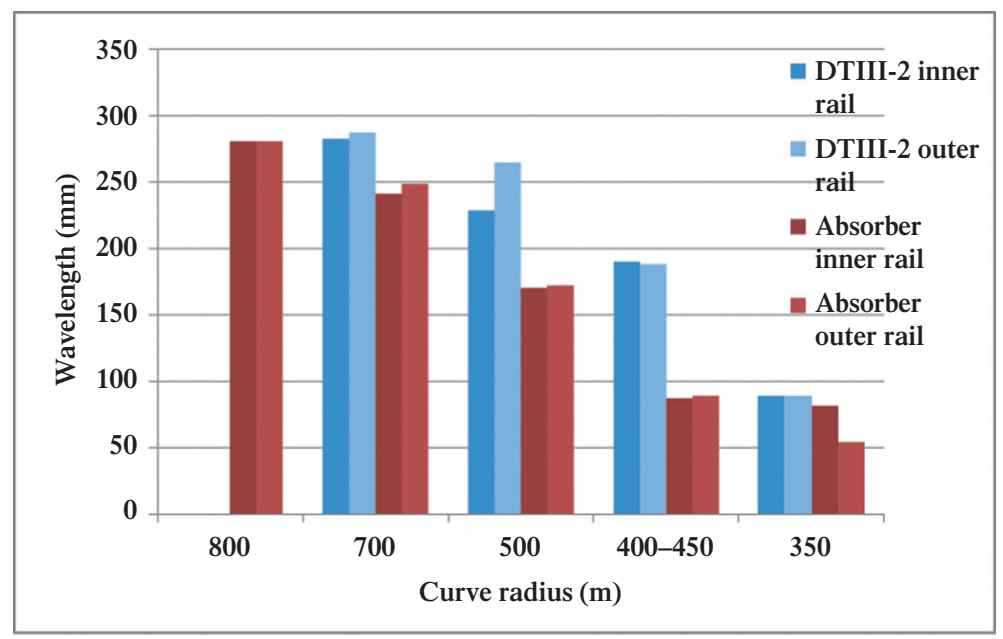

Figure 7: Wavelengths with different radius where monolithic track bed is applied.

Table 2: Contributions of amplitude of different wavelengths.

\begin{tabular}{lcccccccc}
\hline \multirow{2}{*}{$\begin{array}{l}\text { Main wavelength } \\
(\mathrm{mm})\end{array}$} & \multicolumn{2}{c}{$0-100$} & \multicolumn{2}{c}{$100-200$} & \multicolumn{2}{c}{$200-250$} & \multicolumn{2}{c}{$250-300$} \\
\cline { 2 - 9 } & Inner rail & $\begin{array}{c}\text { Outer } \\
\text { rail }\end{array}$ & Inner rail & $\begin{array}{c}\text { Outer } \\
\text { rail }\end{array}$ & Inner rail & Outer rail & Inner rail & Outer rail \\
\hline $\begin{array}{l}\text { Average }(\mathrm{mm}) \\
\text { Triple standard }\end{array}$ & 0.01 & 0.01 & 0.01 & 0.01 & 0.00 & 0.00 & 0.01 & 0.01 \\
$(\mathrm{~mm})$ & 0.42 & 0.43 & 0.44 & 0.50 & 0.31 & 0.34 & 0.36 & 0.37 \\
Range of amplitude & & & & & & & & \\
$(\mathrm{mm})$ & & & & Portion of amplitude $(\%)$ & & \\
$<-0.4$ & 0.31 & 0.44 & 0.5 & 1 & 0.04 & 0.09 & 0.34 & 0.15 \\
$(-0.4,-0.3)$ & 1.19 & 1.05 & 1.8 & 3.05 & 0.67 & 1.23 & 0.99 & 1.21 \\
$(-0.3,0.3)$ & 96.08 & 96.44 & 94.86 & 92.81 & 98.92 & 97.57 & 96.58 & 96.88 \\
$(0.3,0.4)$ & 1.66 & 1.65 & 2.28 & 2.56 & 0.3 & 0.63 & 1.38 & 1.41 \\
$>0.4$ & 0.76 & 0.42 & 0.57 & 0.58 & 0.08 & 0.48 & 0.72 & 0.36 \\
\hline
\end{tabular}



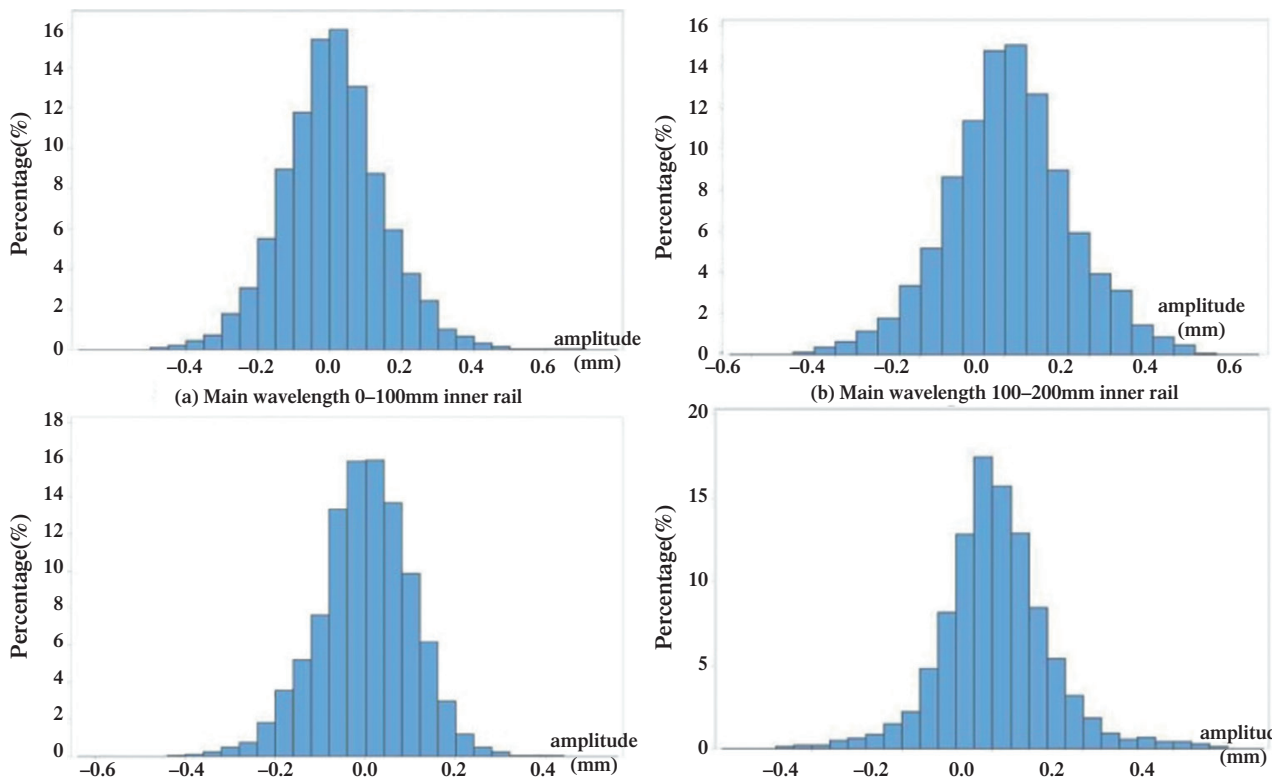

(c) Main wavelength $200-250 \mathrm{~mm}$ inner rail

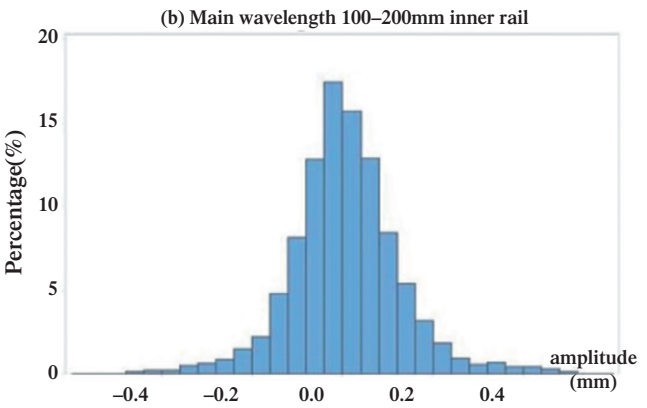

(d) Main wavelength $250-300 \mathrm{~mm}$ inner rail

Figure 8: Distribution of amplitude of different wavelengths on inner rail.
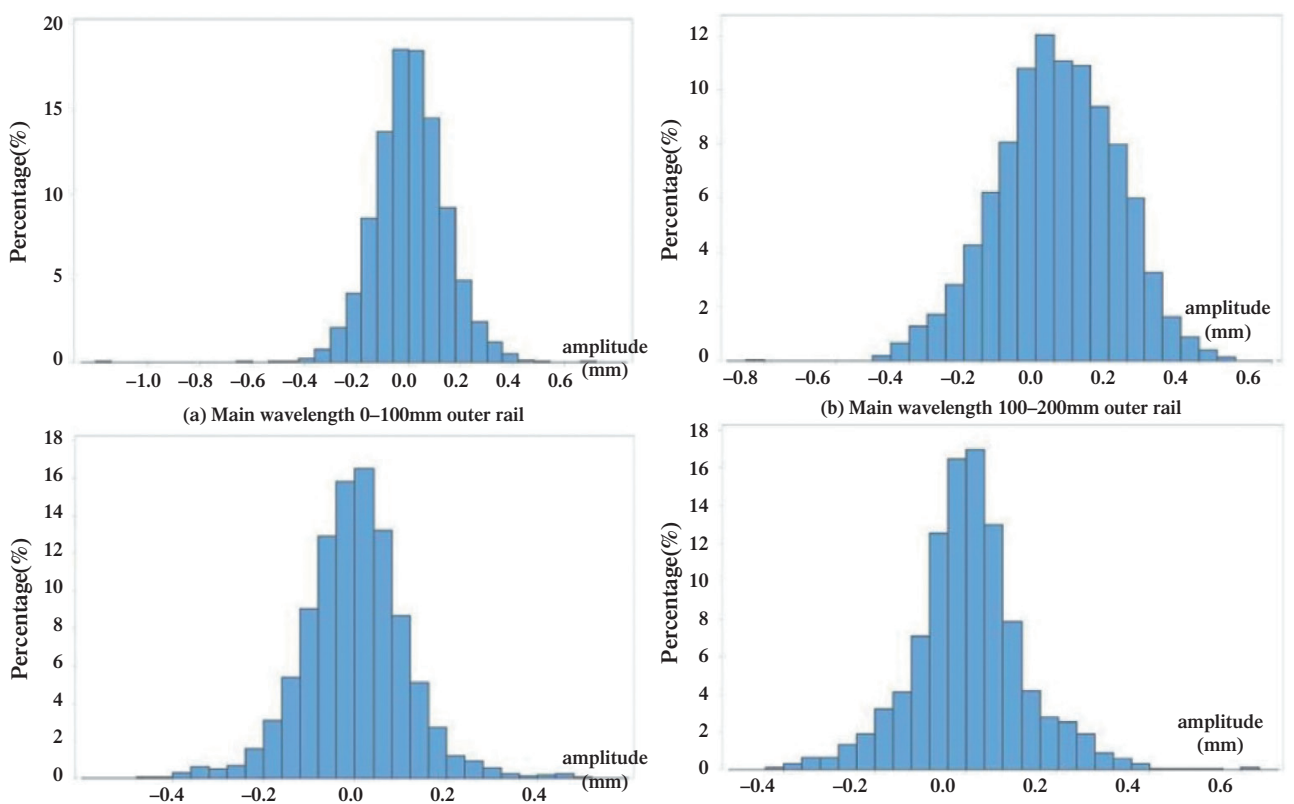

(c) Main wavelength $200-250 \mathrm{~mm}$ outer rail

(c) Main wavelength $250-300 \mathrm{~mm}$ outer rail

Figure 9: Distribution of amplitude of different wavelengths on outer rail. 


\subsection{Distribution of dynamic data}

The effect of rail grinding is considered in this research (Fig. 10). Figure 11 shows the waveform graph of inner/outer rails before/after grinding on a curve at section Xujiahui to Shanghai Natatorium of Shanghai Metro 11. This curve lies at about XK35 + $494-$ XK35 + 620, when monolithic track bed and absorber fasteners, with radius of $350 \mathrm{~m}$, are used. Figure 11 demonstrates vertical forces before/after grinding in about $7 \mathrm{~s}$ after the train passed the measured point (Fig. 12).
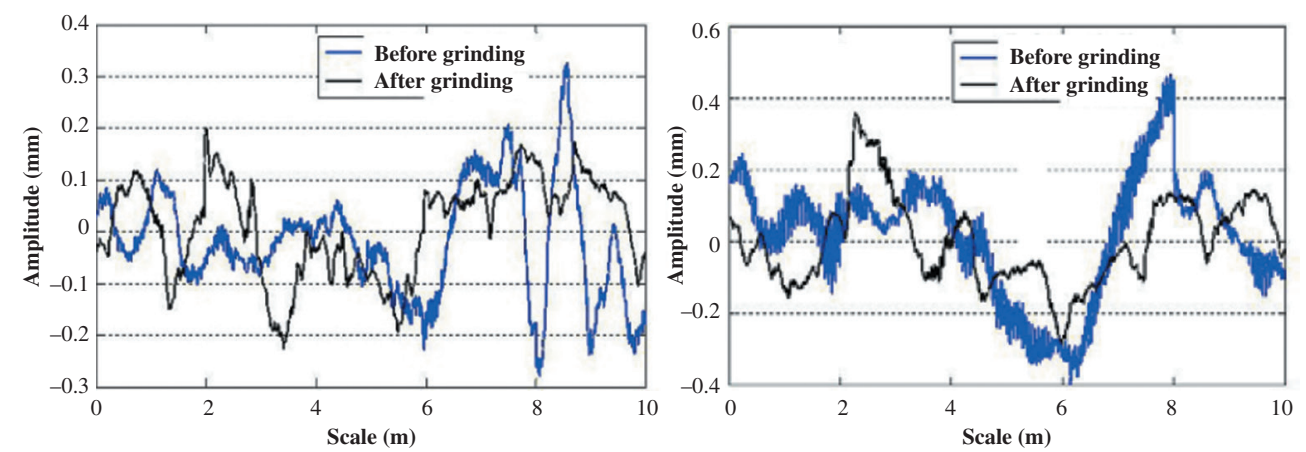

Figure 10: Waveform graph of inner/outer rail before/after grinding.
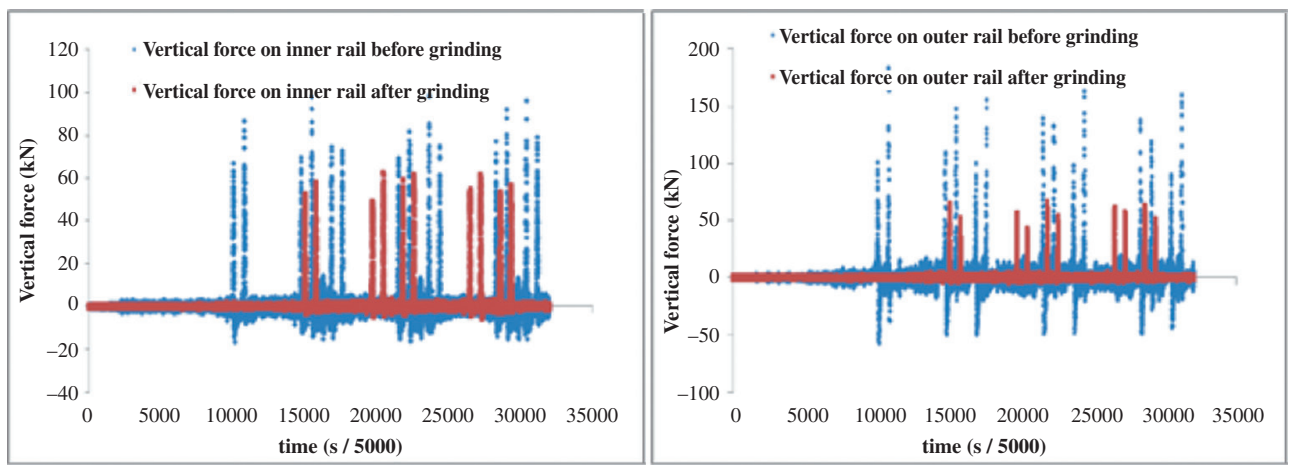

Figure 11: Vertical forces of inner/outer rail before/after grinding.

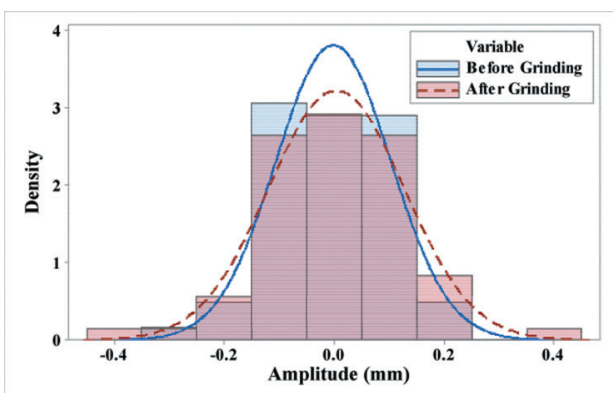

(a) Amplitude's distribution of inner rail

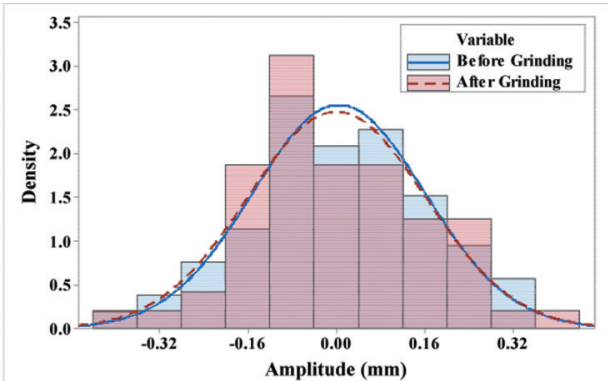

(b) Amplitude's distribution of outer rail

Figure 12: Distribution of amplitude of inner/outer rail before/after grinding. 
As shown in Fig. 11, vertical forces decreased after grinding. In Table 3, the numbers of points amplitude of which is bigger than $0.3 \mathrm{~mm}$ or smaller than $-0.3 \mathrm{~mm}$ decreased, while the number of points amplitude of which is in the range of -0.3 to $0.3 \mathrm{~mm}$ increased. Although there is no proof to show that that decreasing of amplitude is the only cause of decreased vertical forces, we can draw the conclusion that decreased amplitude is helpful for decreasing vertical force.

\subsection{New threshold for corrugation amplitude}

According to in situ data, after grinding, amplitudes that are smaller than $-0.3 \mathrm{~mm}$ or bigger than $0.3 \mathrm{~mm}$ disappeared a lot, which is pretty similar to the triple standard in the contributions of amplitude of different wavelengths. Existed threshold is pretty severe and may increase maintenance work. Here we suggest using the conservative values of triple standard as shown in Table 4, which haven't been verified by applying them on maintenance now.

Table 3: Amplitude contribution before/after grinding.

\begin{tabular}{lcccc}
\hline & \multicolumn{2}{c}{ Before grinding } & \multicolumn{2}{c}{ After grinding } \\
\hline & Inner rail & Outer rail & Inner rail & Outer rail \\
Average $(\mathrm{mm})$ & -0.001 & 0.006 & 0.005 & 0.002 \\
Triple standard & 0.314 & 0.468 & 0.371 & 0.482 \\
$(\mathrm{~mm})$ & & & & \\
& & Number of points amplitude & & 0 \\
$<-0.4 \mathrm{~mm}$ & 0 & 0 & 1 & 2 \\
$(-0.4,-0.3) \mathrm{mm}$ & 0 & 3 & 0 & 2 \\
$(-0.3,-0.2) \mathrm{mm}$ & 3 & 4 & 2 & 15 \\
$(-0.2,-0.1) \mathrm{mm}$ & 7 & 9 & 5 & 12 \\
$(-0.1,0) \mathrm{mm}$ & 22 & 16 & 28 & 13 \\
$(0,0.1) \mathrm{mm}$ & 17 & 10 & 19 & 6 \\
$(0.1,0.2) \mathrm{mm}$ & 12 & 16 & 15 & 1 \\
$(0.2,0.3) \mathrm{mm}$ & 1 & 6 & 1 & 1 \\
$(0.3,0.4) \mathrm{mm}$ & 0 & 2 & 0 & \\
$>0.4 \mathrm{~mm}$ & 0 & 0 & 1 & \\
\hline
\end{tabular}

Table 4: Suggested values for amplitude threshold of different wavelengths.

\begin{tabular}{lcccc}
\hline Main wavelength (mm) & $0-100$ & $100-200$ & $200-250$ & $250-300$ \\
Triple standard (mm) & 0.43 & 0.46 & 0.32 & 0.36 \\
Suggested value (mm) & \pm 0.4 & \pm 0.4 & \pm 0.3 & \pm 0.3 \\
Overrun portion (\%) & 1.07 & 1.07 & 1.09 & 3.43 \\
\hline
\end{tabular}




\section{CONCLUSIONS}

By analysing rail corrugation data and dynamic in situ test data and plotting the contribution of them, we arrived at the following conclusions:

1. Ballast/fastener/curve radius can affect the amplitude and wavelength of corrugation. When preventing corrugation is the primary purpose, our suggestion is using monolithic track bed and floating slab as the ballast and vanguard as the fastener, and the curve radius can be about 400-450 m.

2. The distribution of amplitude at certain wavelengths is approximately normal standard distribution. Using triple standard as the threshold for corrugation amplitude is reasonable.

\section{ACKNOWLEDGEMENTS}

This paper has received the financial aid from International Exchange Program for Graduate Students, Tongji University.

\section{REFERENCES}

[1] Grassie, S.L. \& Kalousek J., Rail corrugation: characteristics, causes, and treatments. Proceedings of the Institution of Mechanical Engineers Part F: Journal of Rail and Rapid Transit, 207(16), pp. 57-68, 1993.

[2] Grassie, S.L., Short wavelength rail corrugation: field trials and measuring technology. Wear, 191, pp. 149-160, 1996.

[3] Sato, Y., Matsumoto, A., \& Knothe, K., Review on rail corrugation studies. Wear, 253, pp. 130-139, 2002.

[4] Torstensson, P.T. \& Nielsen, J.C.O., Monitoring of rail corrugation growth due to irregular wear on a railway metro curve. Wear, 267(1-4), pp. 556-561, 2010.

[5] Wang, G., Chen, G., \& Wu, P., Influence of sleeper support stiffness and damping on wear-type rail corrugation on a tight curve (in Chinese). Journal of Vibration and Shock, 30(2), pp. 99-103, 2011.

[6] Cao, L., Xu, Y., Zhou, Y. \& Zhan, G., Characteristics of passenger evacuation in urban mass transit (in Chinese). Urban Mass Transit, 13(2), pp. 46-46, 2010. 